Research Article

\title{
Evaluation of Changes in Calcium Levels in Patients Suffering from Cancer
}

\author{
Mehwish Saleem $^{1 *}$, Maria Tahir ${ }^{1}$, Maryam Ilyas $^{2}$ and Aqsa Malik ${ }^{2}$
}

${ }^{1}$ Pathology Lab Inmol Hospital, Lahore, Pakistan; ${ }^{2}$ Microbiology Lab Islamia College for Women, Cooper Road, Lahore, Pakistan.

\begin{abstract}
The major need of body is calcium because it is main nutrient for bones. Cancer is more prevalent in males $(n=17) 57 \%$ than females $(n=13) 43 \%$. Cancer can affect level of calcium in body. The most frequent cancer type among males is blood cancer. Electrolytes are minerals carry vital charge. These are essential for maintaining or carrying vital body function. These carry out cell functions i.e hydration, muscle contraction, heart beating and conduction of nerve impulse. These include calcium, magnesium, sodium, potassium, chloride etc. Calcified body parts like teeth and bone contain calcium, which firm the bony parts and important factor in blood clotting and circulation purpose was to evaluate serum calcium level in patient's blood. Blood samples were collected from cancer patients from MAYO hospital LHR during the time period April 2018 to May 2018. Some cancer patients have increased calcium level in blood. Cancer is more prevalent in males $(n=17) 57 \%$ than females $(n=13) 43 \%$. The most frequent cancer type among males is blood 41 cancer $(n=5) 36 \%$, lung cancer $(n=3) \quad 22 \%$ and oral cancer $(n=3) 22 \%$. In females breast cancer $(n=5) 32 \%$ is most prevalent, followed by blood cancer $(n=4) 25 \%$, colon cancer $(n=3) 9 \%$. Cancer patients with hypocalcaemia were $(n=20) 67 \%)$. Cancer patients ranging from 21-40 years have high prevalence of hypocalcaemia $(n=11)$ $57 \%$. Hypocalcaemia in cancer patients is commonly encountered, in hospitalized patients due to side effect of chemotherapy or other drugs.

Received | February 10, 2020; Accepted | January 11, 2021; Published | June 05, 2021

*Correspondence | Mehwish Saleem, Pathology Lab Inmol Hospital, Lahore, Pakistan; Email: rafia_1@yahoo.com

Citation | Saleem, M., Tahir, M., Ilyas, M., Malik, A., 2021. Evaluation of changes in calcium levels in patients suffering from cancer. Journal of Innovative Sciences, 7(1): 136-141.

DOI | https://dx.doi.org/10.17582/journal.jis/2021/7.1.136.141

Keywords | Calcium, Cancer, Hypocalcemia, Male, Female
\end{abstract}

\section{Introduction}

$\mathrm{C}$ alcium is unnecessary growth of body own cells. There are over 100 type of cancers. Calcium reduces proliferation of cell and may cause them to die. Cancer treatments increase the calcium level of body and help in controlling cancer cells. Cancers of different origins have different features.

Carcinomas are originated from body epithelial cells. While sarcomas are from connective tissues i.e fat, vessels etc. Calcium plays crucial role, calcium ions level is firmly regulated in body, where key mineral storage site is bone. Under controlled conditions calcium ions are released in bloodstream from bones (Brini et al., 2013). Parathyroid gland secretes parathyroid hormone from parathyroid gland maintains the level of calcium in body. When blood deprived of calcium it causes to reabsorb more calcium.

Protein coupled receptors are responsible to maintain blood calcium level within normal range by regulating parathyroid hormone $(\mathrm{PTH})$ production. Renal calcium handling modulates cell proliferation 
and differentiation as well as the production of parathyroid hormone related proteins (Chang and Wysolmer 2016).

Hypo and hypercalcemia are both life threatening conditions. Hypercalcemia leads to nerve paralysis or loss of muscle control and hypocalcaemia cause paralysis and milk fever are down syndromes. Myeloma cancers increase calcium to threshold level. Rise in calcium is due to any of above factors CSPR or parathyroid regulation etc. Tumors due to rise in calcium may affect almost every body part. Mainly bronchioles, prostate, myelomas etc.

The majority of bone metastasis causes are breast and prostate cancer. Bone metastasis is common in adults and much common then primary bone cancer. Drugs such as diuretics, fluroides, glucose and laxatives cause decrease in level of calcium. In tumor lysis syndrome, group of abnormalities occur during treatment of cancer where large number of cells are killed off. This condition usually occurs after treatment of lymphomas and leukemia's. Recent advances in our knowledge of normal bone metabolism and calcium regulation have led to new concepts of calcium level with cancer (Cheuk et al., 2014).

\section{Materials and Methods}

Blood samples were collected from Mayo hospital during the time period from April 2018 to May 208. Experimental work was done in the Madina lab. \& Medical Center and Clinical Lab Sir Ganga Ram Hospital, Lahore. Sample was allowed to stand for 10 min before starting the procedure. Blood samples were centrifuge in centrifuge machine for $5 \mathrm{~min}$ at $290 \mathrm{rpM}$. After the centrifugation process the blood serum was separated from the blood cells which sink down in the tube and serum comes on surface. The kit which we use for performing calcium test was RANDOX CALCIUM (Ca). It comes with the four reagent bottles, Standard ( CAL), Buffer (R1), Chromogen (R2), EDTA (R3). Two test tubes were taken and marked as $\mathrm{Ca}$ standard and $\mathrm{Ca}$ Sample $\mathrm{R} 1$ and R2 $(500 \mu \mathrm{l})$ were added to the $\mathrm{Ca}$ Standard with the micropipette. R3 (25 $\mathrm{l}$ ) was added with the micropipette. Color was changed to violet. R1 and R2 $(500 \mu 1)$ were added to the Ca Sample with the micropipette. Blood serum $(25 \mu \mathrm{l})$ was added with the micropipette. Color was changed to violet (Annexure D). Ca standard and $\mathrm{Ca}$ sample was placed in water bath for 10 mins at 370C.Clinical chemistry analyser METROLAB1600 was used for further assay. Firstly method was selected for calcium test which was 16.Read water absorbance of distilled water. Read reagent blank (distilled water). Read standard (Ca standard) note the reading which was $10 \mathrm{mg} / \mathrm{dl}$. Read next sample ( $\mathrm{Ca}$ standard as sample) reading was approximately $10.2 \mathrm{mg} / \mathrm{dl}$. Read next sample (Ca sample with blood serum). Read the reading on screen which can vary between $8.5-10.5 \mathrm{mg} / \mathrm{dl}$ and print it out.

\section{Results and Discussion}

Blood samples were collected from cancer patients from MAYO hospital LHR during the time period April 2018 to May 2018. Total no of cancer patients was thirty $(n=30)$. Thirteen $(n=13) 43 \%$ male cancer patients out of total seventeen $(n=17) 57 \%$ were diagnosed with hypocalcemia (Annexure A). Seven $(n=7) 23 \%$ female cancer patients out of total thirteen $(n=13) \quad 43 \%$ were detected with hypocalcemia (Annexure B). Taken as a whole, out of thirty $(n=30)$ cancer patients twenty $(n=20) 67 \%$ were reported as hypocalcemic and ten $(n=10) 33 \%$ were spotted with normal serum calcium level (Table 1, Figure 1). Mainly the cancer patients were divided in three age groups. Group 1 compose of patients less than twenty years (< $20 \mathrm{yrs}$ ), group 2 compose of patients from twenty one to forty years (21Y-40 yrs) and group 3 was compose of patients fall between forty one to sixty years (41Y$60 \mathrm{yrs})$. Out of seventeen ( $\mathrm{n}=17)$ male cancer patients, three $(n=3)$ were reported fall within the range of < 20 years, six $(n=6)$ were reported fall within the range 21-40 years and eight $(n=8)$ were reported fall within range of 41-60 years (Table 2). Most of the male cancer patients (61\%) diagnosed with hypocalcemia fall within the range of 41-60 years, Four $(n=4) 31 \%$ male cancer patients with hypocalcemia fall in the range of 21-40 years, least $(n=1) 8 \%$ were reported with hypocalcemia fall within range of $<20$ years (Figure 2). Out of thirteen $(n=13)$ female cancer patients, one was reported fall within the range of $<20$ years, ten $(n=10)$ were reported fall within the range $21-40$ years and two $(n=2)$ were reported fall within range of 41-60 years (Table 3). Most of the female cancer patients diagnosed with hypocalcaemia were seven $(n=7)$ fall within the range of 41-60 years, other two age groups were not spotted with any hypocalcemic patients (Figure 3). Collectively most cancer patients diagnosed with hypocalcaemia (53\%) 
were reported to fall within the range of 21-40 years (Figure 4). Least cancer patients with hypocalcemia $(14 \%)$ were reported to fall within the range of $<20$ years (Figure 4). In cancer patients collectively most prevalent cancer type was blood cancer $30 \%$, followed by breast cancer and colon cancer $17 \%$ than lung cancer and oral cancer 13\%. Least occurring cancer type was bone cancer $7 \%$ and uterine cancer 3\% (Table 4, Figure 7). In female cancer patients most Serum calcium in cancer patients according to gender.

Table 1: Investigation of total no. of male and female cancer patients according to serum calcium level.

\begin{tabular}{llll}
\hline Genders & $\begin{array}{l}\text { Total no of Patient with low } \\
\text { patients }\end{array}$ & $\begin{array}{l}\text { Patients with nor- } \\
\text { Calcium level }\end{array}$ & mal Calcium level \\
\hline Males & 17 & 13 & 4 \\
females & 13 & 7 & 6 \\
Total & 30 & 20 & 10 \\
\hline
\end{tabular}

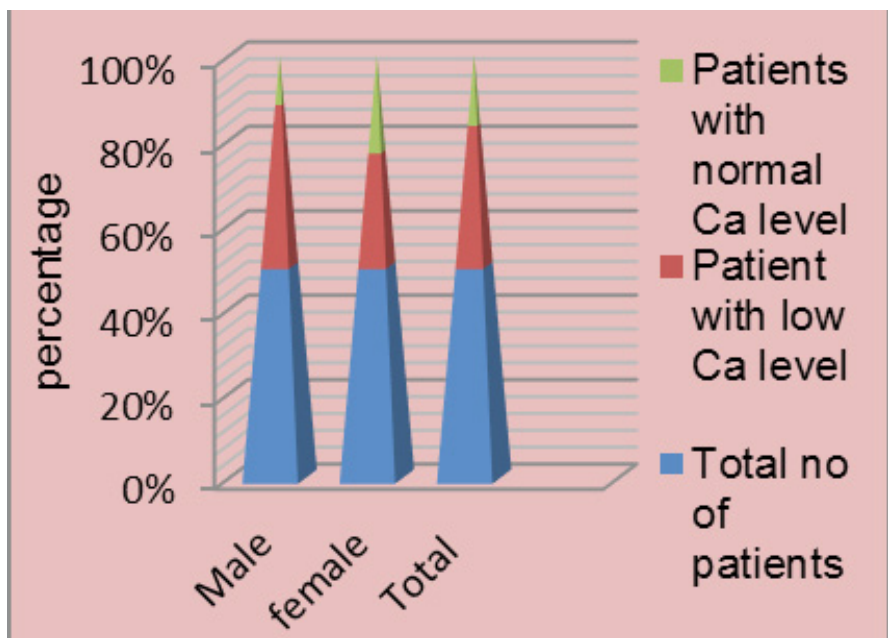

Figure 1: Prevalence of serum calcium level in cancer patients according to gender.

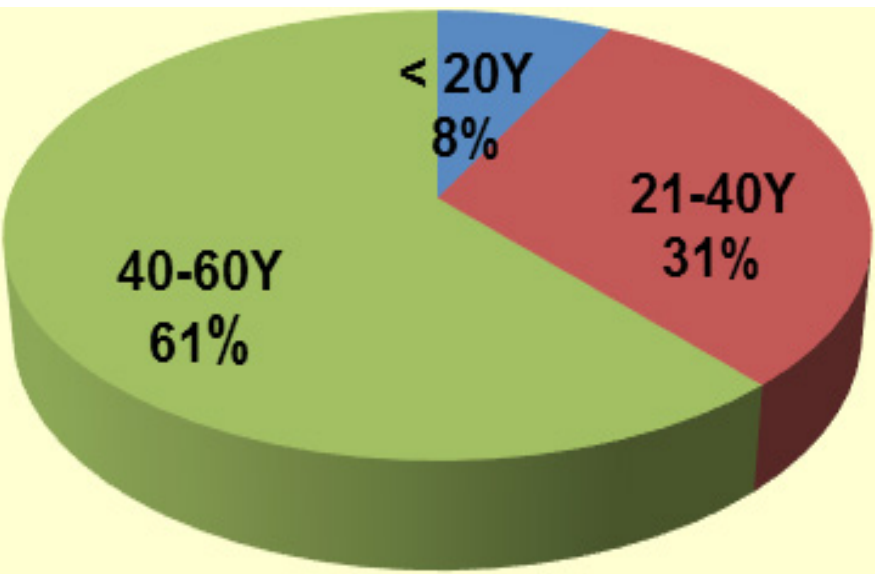

Figure 2: Percentage of low serum calcium level with respect to age groups in male patients.
Table 2: Analysis of serum calcium level according to different age groups in male cancer patients.

Age groups Total no of male with low male with normal

\begin{tabular}{llll} 
& patients & Calcium level & Calcium level \\
\hline$<20 \mathrm{Y}$ & 3 & 1 & 2 \\
$21 \mathrm{Y}-40 \mathrm{Y}$ & 6 & 4 & 2 \\
$41 \mathrm{Y}-60 \mathrm{Y}$ & 8 & 8 & 0 \\
\hline
\end{tabular}

Table 3: Frequency of female cancer patients in different age groups with respect to serum calcium level.

\begin{tabular}{llll}
\hline $\begin{array}{l}\text { Age } \\
\text { groups }\end{array}$ & $\begin{array}{l}\text { Total no of } \\
\text { patients }\end{array}$ & $\begin{array}{l}\text { female with low } \\
\text { Calcium level }\end{array}$ & $\begin{array}{l}\text { female with nor- } \\
\text { mal Calcium level }\end{array}$ \\
\hline$<20 \mathrm{Y}$ & 1 & 0 & 1 \\
$21 \mathrm{Y}-40 \mathrm{Y}$ & 10 & 7 & 3 \\
$41 \mathrm{Y}-60 \mathrm{Y}$ & 2 & 0 & 2 \\
\hline
\end{tabular}

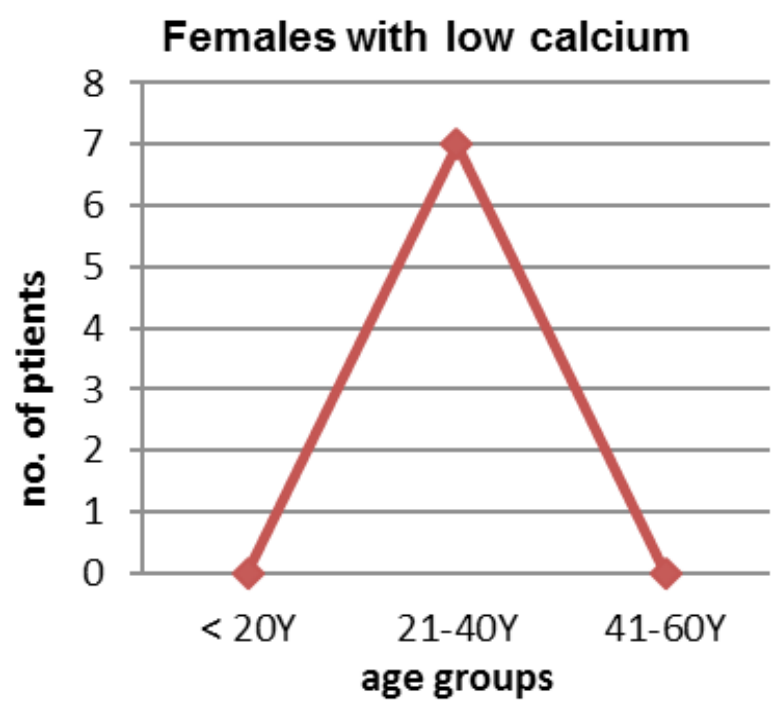

Figure 3: Evaluation of low serum calcium level with respect to age groups in female patients.

Lung cancer is prevalent in our Pakistan. Change in life style, smoking, alcohol consumption etc enhancing its prevalence. Smokers are 10 times more at risk. Similarly addictive of caffeine, niswar etc are more at risk. The result of conducted study reveal, sexual Hormones, dietary habits, exposure to the carcinogens increase cancer risk more in men than women because alcohol consumption, smoking, increase the risk of cancer in male then in females as ratio range in men is 7.4 millon and in women $=6.6$ million cancer are diagnosed (Yavuz, 2016). Total no of cancer patients was thirty $(n=30)$. Thirteen $(n=13)$ $43 \%$ male cancer patients out of total seventeen $(n=17) 57 \%$ were diagnosed with hypocalcemia. Seven $(n=7) 23 \%$ female cancer patients out of total thirteen $(n=13) 43 \%$ were detected with hypocalcemia. Taken 
as a whole, out of thirty $(\mathrm{n}=30)$ cancer patients twenty $(n=20) 67 \%$ were reported as hypocalcemic and ten (n=10) 33\% were spotted with normal serum calcium level (Table 1, Figure 1). Hypocalcemia may affect up to $70 \%$ of cancer patients (Hastbacka et al., 2003) According to conducted study most cancer patients diagnosed with hypocalcemia (53\%) were reported to fall within the range of 21-40 years (Figure 4). Least cancer patients with hypocalcemia (14\%) were reported to fall within the range of $<20$ years (Figure 4). All diagnosed cancer in male $=4.6 \%$ In children $=64.3 \%$ in adults $=31.2 \%$ and in females $=2.0 \%$ diagnosed (Sarwar and Saqib, 2016). Results of the study reveals that in cancer patients collectively most prevalent cancer type was blood cancer 30\%. In female cancer patients percentage was 25\% (Figures 5) and in male cancer patients blood cancer was $36 \%$ (Figure 6). Blood cancer effect the people in every age ,if it occurs in child then we called it leukaemia. Accute lymphoblast (ALL) what is acute? The lymphatic system lymphoid cells are burst so, this is called the accute lymphoblast (Altaf, 2017). Among female cancer patients most frequent cancer type was breast cancer 32\% (Figures 5).

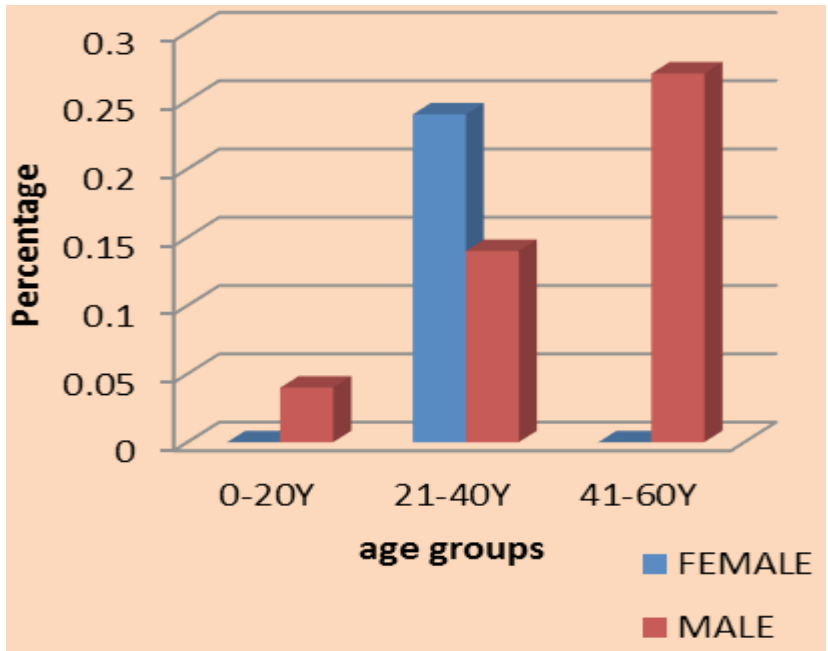

Figure 4: Comparison of hypocalcemia of female and male cancer patients with respect to age groups.

Breast cancer possess a major health issues for women in all over the world one million women diagnose every year for breast cancer (Altaf, 2017). Among female cancer patients most frequent cancer type was breast cancer 32\% (Figures 5) (Menhas and Umer, 2015). Collectively patients was $13 \%$. Male patients 22\% (Figure 6) and least prevalent in 6\% (Figures 5) (Ferlay, 2010). Bone cancer accounts least prevalence of total cancer rate. Rate of bone cancer is more in males 7\% (Figures 5) than female patients 6\% (Figure
6). Bone malignancies accounts for only $0.2 \%$ of all malignancies in the USA and UK; however in children it account approximately $5 \%$ of malignancies (Dorfman and Czerniak, 1995). Colon cancer account 9\% of total cancer rate which was in male patients was $14 \%$ and least frequents in female patients $9 \%$ (Figures 5 and 6). Global research shows rate of colon cancer which is $9 \%$ of total cancer rate.

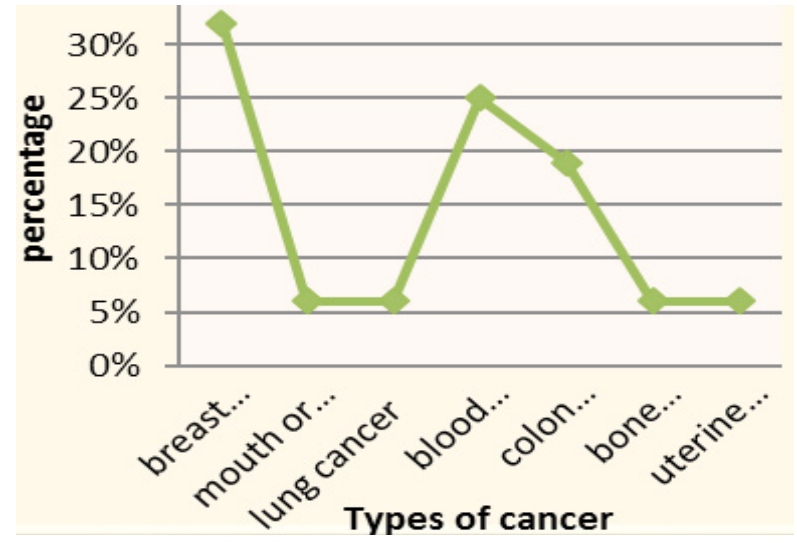

Figure 5: Percentage of different cancer types diagnosed in female cancer patients.

Table 4: Frequency of different cancer types among male and female patients.

\begin{tabular}{llll}
\hline & $\begin{array}{l}\text { Total no. of } \\
\text { patients }\end{array}$ & $\begin{array}{l}\text { Female } \\
\text { patients }\end{array}$ & $\begin{array}{l}\text { Male } \\
\text { patients }\end{array}$ \\
\hline Breast cancer & 5 & 5 & 0 \\
oral cancer & 4 & 1 & 3 \\
Lung cancer & 4 & 1 & 3 \\
Blood cancer & 9 & 4 & 5 \\
Colon cancer & 5 & 3 & 2 \\
Bone cancer & 2 & 1 & 1 \\
Uterine cancer & 1 & 1 & 0 \\
\hline
\end{tabular}

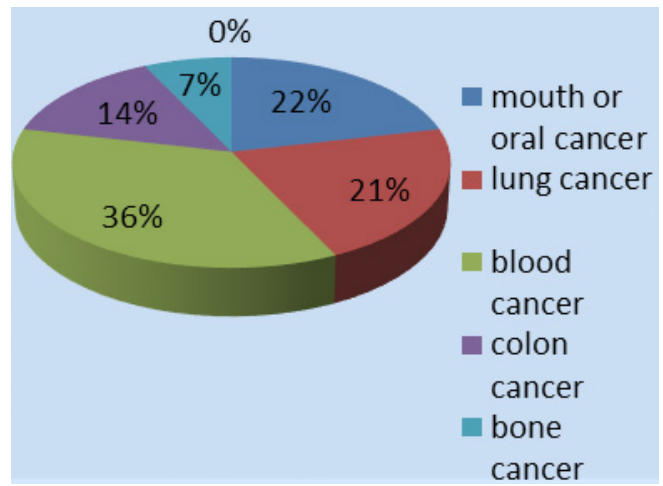

Figure 6: Percentage of different cancer types diagnosed in male cancer patients.

Another prevalent type of cancer is blood cancer. It effect all age groups. In child decrease leukocytes or acute lymphoblasts are major cause of mortality. 
About 70 percent of cancer cases are blood cancers. Breast cancer also gaining popularity mainly due to lack of awareness among women. Now its awareness has been rising by diff govt projects, health care departments and NGOS.

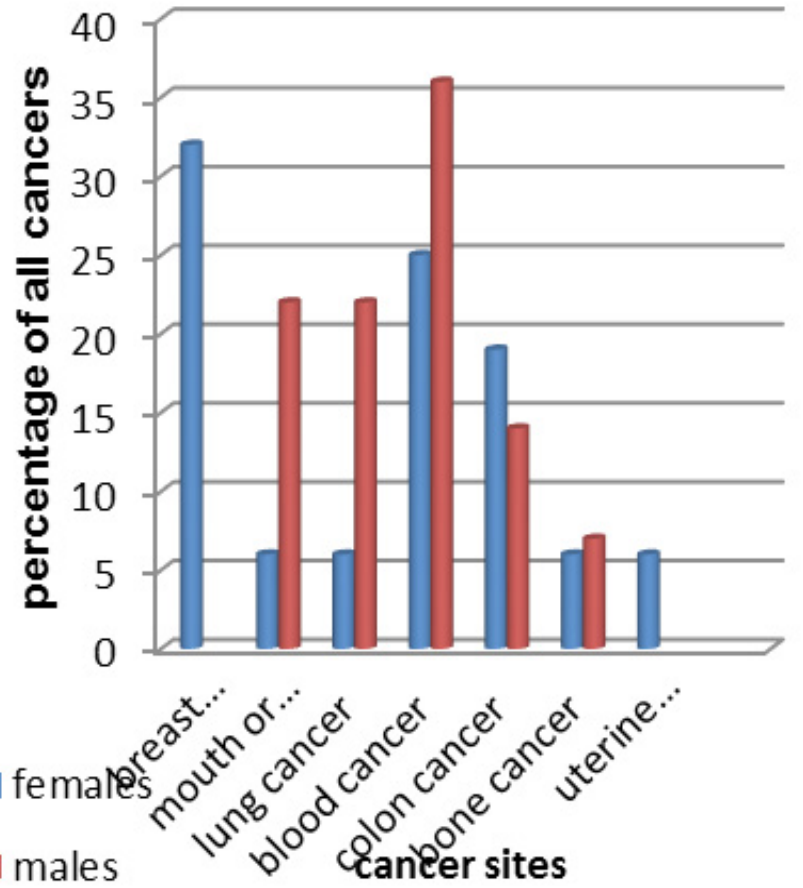

Figure 7: Proportion of cancer by site in female and vale cancer patients.

\section{Conclusions and Recommendations}

In patients with cancer, hypocalcaemia is common. Different mechanisms have been identified which are responsible for hypocalcemia in cancer patients. Cancer may reduced activity of parathyroid glands and deficiency of vitamin that cause hypocalcemia. Tumor lysis syndrome is also responsible for causing hypocalcemia. Drugs used in cancer treatments show adverse effect in reducing serum calcium level by effecting vitamin $\mathrm{D}$ concentration. Studies indicate that males are more prone to cancer manly blood cancers, females have more prevalence of breast cancer.

\section{Novelty Statement}

Evaluation of changes in calcium level in cancer patients is actually a marker or risk associated factor with cancer. Its may also called liquid biopsy to predict the cancer in coming future.

\section{Author's Contribution}

Mehwish Saleem designed the study and edit the paper and further corre-sponding. Maria Tahir and Kishwer Badar helped in writing paper.

\section{Conflict of interest}

The authors have declared no conflict of interest.

\section{References}

Acqueline, K., Anderson, C., Scott, M.L., 2017. Physical activity, sedentary behaviour, diet, and cancer: an update and emerging new evidence. Lancet Oncology, 18(8): 2017. https://doi. org/10.1016/S1470-2045(17)30411-4

Altaf, M., 2017. Blood cancer in Pakistan. Pakistan Observer, 3: 125.

Brini, M., Ottolini, D., Calì, T. and Carafoli, E., 2013. Calcium in health and disease. In Astrid Sigel, Helmut Sigel and Roland K.O. Sigel. Interrelations between Essential; Tokarz, An Metal Ions and Human Diseases. Metal Ions in Life Sciences. 13: 81-137. https://doi. org/10.1007/978-94-007-7500-8_4

Chang, W. and Wysolmerski, J. 2016. CalciumSensing Receptor Promotes Breast Cancer by Stimulating Intracrine Actions of Parathyroid Hormone-Related Protein. Cancer Res. Sep 15;76(18):5348-60.

Cheuk, D.K., Chiang, A.K., Chan, G.C. and Ha, S.Y., 2014. Urate oxidase for the prevention and treatment of tumour lysis syndrome in children with cancer. Cochrane Database of Systematic Reviews. 8: 6945. https://doi. org/10.1002/14651858.CD006945.pub3

Dorfman, H.D. and Czerniak, 1995. Bone cancers. Cancer, 75: 203$210 . \quad$ https://doi.org/10.1002/10970142(19950101)75:1+<203::AID-CNCR2820751308>3.0.CO;2-V

Ferlay, J., Shin, H.R., Bray, F., Forman, D., Mathers, C.D. and Parkin, D., 2010. Globocan 2008, Cancer incidence and mortality worldwide. IARC Cancer Base No. 10, International Agency for Research on Cancer.

Goldner,W., 2016. Cancer-Related Hypercalcemia. Journal of Oncology Practice. 2: 433-435.

Haggar, F.A. and Boushey, R.P., 2009. Colorectal cancer epidemiology: Incidence, mortality, survival, and risk factors. Clin. Colon Rectal Surg., 22: 191-197. https://doi. org/10.1055/s-0029-1242458

Hastbacka, J. and Pettila, V., 2003. Prevalence and 
predictive value of ionized hypocalcemia among critically ill patients. Acta Anaesthesiol Scand., 47: 1264-1269. https://doi.org/10.1046/j.13996576.2003.00236.x

Lipton, 2008. Emerging role of bisphosphonates in the clinic-antitumor activity and prevention of metastasis to bone. Cancer Treatment. Suppl., 6: 25-30. https://doi.org/10.1016/j. ctrv.2008.03.008

Macedo, F., Ladeira, K., Pinho, F., Saraiva, N., Bonito, N., Pinto, L. and Gonçalves, F., 2017. Bone metastases: An overview. Oncology Reviews. 11(1):23-67.https://doi.org/10.4081/ oncol.2017.321

Mehnhas, R. and Umer, S., 2015. Breast Cancer among Pakistani Women. Iran J. Public Health, 44(4): 34-90.

Minisola, S., Pepe, J., Piemonte, S. and Cipriani, C., 2015. The diagnosis and management of hypercalcaemia. British Medical Journal, 350: 2723. https://doi.org/10.1136/bmj.h2723

Mitchell, D.M., Regan, S. and Cobley, M.R., 2012. Long-term followup of patients with hypoparathyroidism. J. Clin. Endol. Metab., 97: 4507-4514. https://doi.org/10.1210/jc.20121808

Murphy, E.W., 2009. Hypocalcemia. Medicine, 37(9): 465-468. https://doi.org/10.1016/j. mpmed.2009.06.003

Parvizi, J., 2010. High yield orthopaedics E-Book. Elsevier Health Sciences. 1: 65-98.

Sarwar, M.R. and Saqib, 2016. Cancer prevalence, incidence and mortality rates in Pakistan in 2012. Journal Cogent Medicine, 2(4): 8-12. https://doi. org/10.1080/2331205X.2017.1288773

Skrajnowska, D., Bobrowska-Korczak, B. and Tokarz, A., 2017. Current medicinal chemistry, 24: 2017. https://doi.org/10.2174/0929867324 666170913102834

Twycross, R. and Wilcock, A., 2001. Symptom management in advanced cancer (third edition). Radcliffe Publishing, Abingdo. pp. 126.

Yavuz, A., 2016. More boys are diagnosed with cancer than girls worldwide why? The Conversation, 2: 52. 